\title{
VIGILÂNCIA CIVIL SOBRE AS PRÁTICAS DE COMUNICAÇÃO DAS ORGANIZAÇÕES PRIVADAS: \\ LIMITES DA ATUAÇÃO DA IMPRENSA E OS DESAFIOS DO MONITORAMENTO PELOS PÚBLICOS
}

\author{
CIVIL SURVEILLANCE OF COMMUNICATIONS ON PRIVATE \\ ORGANIZATIONS: LIMITS OF THE PRESS AND THE CHALLENGES OF \\ PUBLIC MONITORING
}

\section{VIGILANCIA CIVIL SOBRE LAS PRÁCTICAS DE COMUNICACIÓN DE LAS ORGANIZACIONES PRIVADAS: \\ LOS LÍMITES DE LA ACTUACIÓN DE LA PRENSA Y LOS RETOS DEL MONITOREO POR PARTE DE LOS PÚBLICOS}

Márcio Simeone Henriques

Doutor, Universidade Federal de Minas Gerais simeone@ufmg.br

Daniel Reis Silva Mestrando, Universidade Federal de Minas Gerais daniel_reis@outlook.com

\begin{abstract}
Resumo
O artigo aborda a questão da vigilância sobre práticas de comunicação das organizações privadas. Por meio de uma análise sobre o surgimento e o desenvolvimento, nos últimos anos, de iniciativas de vigilância civil voltadas para a denúncia de práticas abusivas de comunicação empregadas pelas organizações, evidencia constrangimentos que limitam a atuação da imprensa no monitoramento dessas atividades. Reflete também sobre a existência de desafios e entraves enfrentados pelos públicos na tentativa de exercer diretamente o papel de vigilância sobre as organizações privadas.
\end{abstract}

Palavras-Chave: Relações Públicas. Imprensa. Opinião Pública.

\begin{abstract}
The article encompasses the matter of surveillance over communication practices of the private sector. Through the analysis of the recent rise and development of civil surveillance focused on denouncing abusive communication employed by such organizations, it highlights constrains that limits press role on monitoring these activities. It also reflects about the existence of challenges and obstacles faced by the public when trying to perform a direct role in supervise private organizations.
\end{abstract}

Esta obra está licenciada sob uma Licença Creative Commons 
Keywords: Public Relations. Press. Public Opinion.

\section{Resumen}

El artículo aborda la cuestión de la vigilancia de las prácticas de comunicación de las organizaciones privadas. A través de un análisis del surgimiento y desarrollo de iniciativas de vigilancia civil destinadas a denunciar las prácticas abusivas de comunicación empleadas por las organizaciones en los últimos años, destaca las limitaciones en el papel de la prensa para el monitoreo de estas actividades. También refleja sobre la existencia de retos y obstáculos que enfrentan los públicos en un intento de ejercer una vigilancia directa sobre las organizaciones privadas.

Palabras-Clave: Relaciones públicas. Prensa. Opinión pública.

\section{INTRODUÇÃO}

A quem cabe a vigilância da atuação pública das organizações privadas? Apesar de compreensível no contexto social contemporâneo, tal questionamento passou a fazer sentido apenas a partir do final do século XIX, período que marca o início da tomada de consciência das organizações privadas sobre a necessidade de justificação e legitimação públicas de suas ações. O desenvolvimento das atividades de Relações Públicas e Comunicação Organizacional no século seguinte amplificou a relevância da questão, na medida em que suas práticas - endereçadas não para o indivíduo como pessoa privada, mas sim como parte de um público - compreendem a tentativa de intervir estrategicamente na formação da opinião pública.

Os esforços cada vez mais sistematizados e abrangentes das organizações na tentativa de conquistar o apoio da opinião pública para suas razões privadas, ancorados em técnicas de comunicação instrumentalizadas a partir da psicologia e da sociologia, constituem um ponto fundamental na sociedade democrática moderna, moldando o debate existente e tornando-se um fenômeno chave para a compreensão da esfera pública atual. Ao mesmo tempo em que se tornava onipresente na vida pública, esta atuação deu origem a uma série de preocupações sobre seus limiares éticos e morais, emergindo questionamentos sobre o ponto em que cruzaria a fronteira entre o democraticamente aceitável e o que constituiria uma prática abusiva de distorção da percepção pública por aqueles que detêm o poder financeiro (HABERMAS, 1984; CHOMSKY e HERMAN, 2002).

Enquanto o desafio de formular condutas aceitáveis e delimitações éticas para a atuação pública das organizações privadas foi encarado por uma diversidade de atores nas 
últimas décadas - seja em organizações profissionais de Relações Públicas e seus códigos de ética, seja no âmbito teórico pela tentativa de promover uma abordagem ética para a atividade ou ainda pelo próprio governo, que passou a regulamentar alguns dos meandros da atuação -, pouca ênfase foi dada para a questão da vigilância dessas ações, que permanece um aspecto aberto e problemático. Quem deve revelar quando as práticas de comunicação das organizações distorcerem informações sobre seus interesses privados, mentirem e criarem falsos fatos mostrando supostos bem públicos em suas ações, quando simularem apoios públicos ou plantarem notícias falaciosas? Muitas vezes a responsabilidade por essa vigilância recai sobre a imprensa, imbuída de sua tradicional característica de "cão de guarda". Mas, enquanto as limitações da função de "cão de guarda" relacionada ao poder público são objetos de reflexões e estudos no âmbito político, pouco é explorado sobre as condições da imprensa de desempenhar esse papel e abastecer os públicos de informações sobre práticas abusivas de comunicação realizadas pelas organizações privadas.

É ao redor da questão da vigilância que o presente artigo orbita, com o intuito de refletir sobre aspectos primordiais que permeiam o tema. Não apenas as limitações da imprensa nos despertam a atenção para o assunto, mas um novo elemento que surge nos últimos anos no intrincado cenário composto pelas organizações, governos, mídia e opinião pública nos encoraja a retornar ao questionamento sobre a vigilância da atuação pública das organizações privadas: o surgimento de uma série de iniciativas originadas na sociedade civil e voltadas para a denúncia de práticas abusivas de comunicação realizadas pelas organizações. São portais na internet e wikis $^{1}$ que, diferentemente do que acontecia até então, vão além da denuncia pontual ou da crítica generalizada, começando a tomar a forma de redes de radares de vigilância sobre o tema, especialmente nos Estados Unidos e no Reino Unido.

O surgimento e a atuação dessas redes nos permitem lançar novas luzes sobre o problema da vigilância apresentado anteriormente. A principal mudança é que são iniciativas do próprio público, justificando sua atuação na defesa de um interesse comum. Nesse sentido, há o deslocamento daquele que é comumente considerado o eixo primordial da vigilância, a imprensa, com os públicos sendo alçados para também ocuparem tal posição. O mais instigante é que, em seguida, os públicos dirigem parte de suas críticas justamente contra a imprensa, denunciando-a não apenas por uma suposta falha na vigilância, mas como parte integrante do próprio problema.

1 Conjunto de páginas interligadas que podem ser editadas livremente, permitindo a criação de conteúdos colaborativos. 
Realizamos um estudo exploratório sobre alguns dos principais mecanismos e redes de vigilância civil, buscando analisar as atividades e estratégias que empregam, como forma de desvelar facetas comumente despercebidas ou desconsideradas sobre o assunto. Iremos, nesse sentido, traçar um percurso a partir da descrição dessa rede, para, em seguida, abordar algumas das tensões trazidas à tona pela sua existência e atuação: os limites da imprensa como "cão de guarda" no que tange às práticas de comunicação das organizações privadas, bem como os constrangimentos e dilemas da própria vigilância civil sobre as organizações privadas.

\section{CONTORNOS DE UMA REDE DE VIGILÂNCIA}

Talvez o maior expoente dos movimentos de vigilância e denúncia das práticas de comunicação abusivas empregadas pelas organizações privadas seja o Center for Media and Democracy (CMD). O CMD é uma organização não lucrativa fundada pelo ativista John Stauber em 1993, nos Estados Unidos. O germe da iniciativa data da década de 1980, quando a atuação de Stauber em um grupo ativista contra hormônios bovinos geneticamente modificados (rGHB da Monsanto) o colocou em contato com práticas de comunicação que lhe chamaram a atenção tanto pelo seu viés manipulador como por não figurarem na imprensa (GUNN, 2012). Stauber afirma que foi a falta de um "cão de guarda" sobre o assunto que levou ao início do CMD, pensado como uma "instituição independente e não partidária

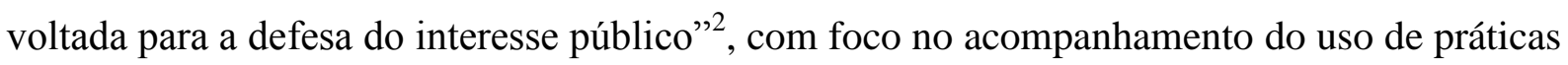
de relações públicas por parte de corporações e do governo.

A primeira ação do CMD, que permanece até hoje como sua principal marca, foi a criação de um boletim trimestral chamado PRWatch ${ }^{3}$. Convertido para um site em 2002, o PRWatch tem como slogan a frase "denunciando $\operatorname{spin}^{4}$ e desinformação desde 1993" (tradução nossa), sendo sua missão declarada expor a verdade sobre campanhas que visam enganar o público, com foco especial na prática do spinning como forma de manipular determinados aspectos de uma controvérsia pública. O site conta com colaboradores de várias

\footnotetext{
2 Disponível em: <www.prwatch.org/cmd>, acesso em 20 de ago. de 2013.

3 Disponível em: <www.prwatch.org〉, acesso em 20 de ago. de 2013.

${ }^{4}$ O termo spin era inicialmente uma expressão do baseball sobre a tentativa do arremessador de controlar a trajetória da bola. Posteriormente, passou a ser utilizado como a tentativa de apresentar uma questão com a melhor luz possível e prover certa interpretação tendenciosa para os fatos, sendo hoje um sinônimo de distorção de informações e de práticas enganosas para manipular a opinião pública.
} 
áreas, especialmente jornalistas, advogados e políticos e produziu na sua trajetória denúncias sobre o uso das relações públicas por diversas indústrias, como a do tabaco, da energia e de planos de saúde, todos marcados por um forte viés de manipulação. O CMD produziu também obras de denúncia visando captar a atenção dos públicos para as práticas abusivas realizadas por grandes organizações, como Toxic Sludge is good for you (1995) e Trust us, we're experts! (2003), ambos de John Stauber e Sheldon Rampton.

Em 2003, o CMD deu inicio ao seu mais ambicioso projeto: o SourceWatch ${ }^{5}$, uma enciclopédia virtual colaborativa nos moldes da Wikipédia, que visa reunir denúncias de grupos e técnicas que tentam moldar a opinião e a agenda pública. A iniciativa conta com o perfil de profissionais e agências de relações públicas, grupos de lobby e detalhes sobre práticas abusivas, com destaque para o spinning, o uso de especialistas para defender produtos ou campanhas, o astroturfing - prática que simula o apoio público voltado para uma causa - e os front groups - prática que cria e financia grupos que defendem determinadas causas ou agendas enquanto se passam por iniciativas espontâneas da sociedade.

Com quase dez milhões de acessos e mais de 65 mil artigos, o SourceWatch é um dos vinte maiores "wikis" privados do mundo ${ }^{6}$, podendo ser considerado como o elemento central dessa rede de vigilância ao criar um ambiente de troca de informações e experiências sobre o assunto, contando com políticas especiais para proteção de denunciantes e com uma atuação global, incluindo denúncias de práticas na Europa, Austrália e Rússia. O SourceWatch também vincula e presta suporte a outras ações do CMD, como o recente ALECexposed ${ }^{7}$, uma investigação realizada em conjunto com o periódico The Nation ${ }^{8}$ que conquistou repercussão nacional ao desvelar como o "ALEC - American Legislative Exchange Council" era utilizado por corporações como um front group para aprovar legislações de acordo com seus interesses privados.

Ações nos mesmos moldes do PRWatch e do CMD podem ser encontradas também no Reino Unido. O principal exemplo é o SpinWatch ${ }^{9}$, uma organização fundada em 2004 com o objetivo de monitorar o papel das relações públicas e do spinning na sociedade britânica, visando promover uma melhor compreensão sobre práticas abusivas de comunicação

\footnotetext{
${ }^{5}$ Disponível em: <www.soucewatch.org>, acesso em 20 de ago. de 2013.

6 Segundo os dados do WikiMedia, website especializado em assuntos "meta-wiki". Disponível em: <www.wikimedia.org>, acesso em 20 de ago. de 2013.

${ }^{7}$ Disponível em: <www.alecexposed.org>, acesso em 20 de ago. de 2013.

${ }^{8} \mathrm{O}$ mais antigo periódico semanal de circulação continua dos Estados Unidos, voltado para questões políticas e culturais, e com declaradas tendências esquerdistas.

${ }^{9}$ Disponível em: <www.spinwatch.org>, acesso em 20 de ago. de 2013.
} 
utilizadas por corporações e grupos lobistas. O SpinWatch é encabeçado por jornalistas, pesquisadores e professores, entre eles David Miller, professor de sociologia da Universidade de Bath, e William Dinan, professor de sociologia da Universidade de Strathclyde, autores de diversos livros sobre o assunto, como A Century of Spin (2007) e Thinker, Faker, Spinner, Spy (2007). A iniciativa conta com um wiki, a PowerBase ${ }^{10}$, que cataloga descrições e detalhes de agências e práticas de relações públicas, campanhas corporativas e lobistas.

Os contornos dessa rede de vigilância civil enfraquecem quando nos afastamos do eixo anglo-americano $^{11}$. Em outros países podemos perceber o predomínio de iniciativas menos sistematizadas e de caráter mais pontual, especialmente por blogs e redes sociais. Mas mesmo algumas dessas iniciativas preservam a ideia de uma rede de vigilância, sendo pautadas pelos conhecimentos já construídos em comunidades como o SourceWatch e contribuindo com novas informações. É o caso do BahrainWatch ${ }^{12}$, uma organização formada por acadêmicos e ativistas ligados ao Bahrein para promover a transparência e o accountability do governo local e das corporações que atuam no país. Uma das suas iniciativas é a vigilância da atuação de agências multinacionais de relações públicas contratadas pelo governo e corporações aliadas ao poder estatal, o que gerou uma lista com o valor e duração de cada contrato, bem como um perfil sobre as agências e a atuação delas, tanto no país como também fora dele. Para a construção desse perfil, várias das informações originaram-se das redes de vigilância nos EUA e no Reino Unido, e por sua vez esses bancos de dados foram atualizados com as investigações sobre a atuação delas no Bahrein.

Mas afinal, o que significa o surgimento e a proliferação de iniciativas de vigilância civil nos últimos anos? No seu âmago, elas evidenciam a permanência de um problema que nunca foi realmente superado sobre o papel de vigiar a atuação pública das organizações privadas, desmontando a ideia de que a imprensa está sempre vigilante sobre o assunto. É um ponto comum nessas redes a insatisfação com a mídia e a necessidade de ação por parte dos públicos, já que "os jornalistas falharam em suas responsabilidades" (STAUBER; RAMPTON, 2003, p.308, tradução nossa). A imprensa não é criticada apenas por não exercer a vigilância, mas também por contribuir para a existência e efetividade das práticas abusivas que ela deveria denunciar. Um exemplo ocorre quando a imprensa "não revela ao público

\footnotetext{
10 Disponível em: <www.powerbase.info>, acesso em 20 de ago. de 2013.

11 Não coincidentemente os dois países em que a atividade de Relações Públicas mais se desenvolveu e sedes das maiores agências multinacionais da área.

12 Disponível em: <www.bahrainwatch.org>, acesso em 20 de ago. de 2013.
} 
certas informações de que ela já tem conhecimento", como a utilização de fontes indicadas e/ou ligadas às organizações sem que esse fato seja esclarecido nas matérias (idem, p. 309).

A declaração categórica sobre como a imprensa falha no seu papel deve ser tomada com cautela. Existem exemplos em que a mídia desempenhou efetivamente a função de vigia, trazendo à tona informações de interesse público, desmantelando táticas voltadas para manipular a opinião pública e fornecendo visibilidade para que tais assuntos pudessem desencadear o debate público - cobrando a prestação de contas por parte dos envolvidos nos atos. O que o grande volume de denúncias proveniente dessas redes civis sugere não é o fracasso da imprensa, e sim a existência de limites relacionados à sua atuação como vigia da atuação pública das organizações privadas, limites esses que podem ser investigados a partir de indícios revelados pelas iniciativas da vigilância civil.

\section{LIMITAÇÕES DA IMPRENSA NO PROCESSO DE VIGILÂNCIA}

Uma das mais tradicionais funções da imprensa na teoria democrática é a de "cão de guarda", um papel de vigilante que procura monitorar aqueles que detêm uma posição de autoridade para denunciar abusos e práticas de corrupção em nome do interesse público, de modo a constituir um sistema de checks and balances capaz de expor a ação de governantes e corporações ao escrutínio público (NORRIS, 2000; MAIA, 2008; CURRAN, 2000). Apesar das conceituações mais contemporâneas sobre a função serem imbuídas também do aspecto de vigilância das organizações privadas, é importante perceber que essa não era uma preocupação existente quando a visão foi originalmente formulada.

Os primórdios da função de vigilância por parte da imprensa remontam à tradição liberal do século XVIII, período em que o jornalismo de opinião começou a tomar forma. $\mathrm{O}$ Estado era, naquele momento, o detentor único do poder, e as instâncias de debate racional dos públicos deveriam ser protegidas de suas intervenções para que pudessem, efetivamente, vigiar o governo (CURRAN, 2000; HABERMAS, 1984). Nessa visão, a mídia deveria ser livre das amarras e regulamentações governamentais, sob o risco de perder sua capacidade de ação.

O subsequente desenvolvimento do modelo de imprensa como empreendimento, centrado no viés dos negócios e concentrado nas mãos do big business, bem como o surgimento e popularização de novas tecnologias como o rádio e a televisão, marcaram uma mudança radical no cenário da mídia. As novas tecnologias, em especial, detinham um poder 
tão grande de influenciar a opinião pública que deviam ser a principio tornadas públicas - este seria o único meio de preservar a função pública dessas mídias e evitar o abuso do poder corporativo (HABERMAS, 1984), dando origem a uma função de "cão de guarda" distinta do ideal liberal, em que as organizações privadas também devem ser vigiadas. Nas últimas décadas, com o avanço de um modelo neoliberal de governo em grande parte do mundo ocidental, o número de veículos da mídia se multiplicou ao mesmo tempo em que o controle sobre o aparato midiático se concentrou em um número progressivamente menor de corporações, dando origem aos gigantescos conglomerados midiáticos da atualidade. $\mathrm{O}$ debate sobre o papel de "cão de guarda" da imprensa se acentuou ainda mais com os questionamentos sobre como a mídia, controlada por essas corporações, poderia exercer uma função de vigilância sobre as organizações privadas.

Segundo Curran (2000), ainda hoje tal debate é marcado por visões radicais nas quais a mídia controlada por corporações serviria apenas aos interesses corporativos e fecharia os olhos para os abusos cometidos pelas corporações (HERMAN e CHOMSKY, 2002), e a mídia controlada pelo Estado seria um instrumento de difusão dos interesses estatais, não exercendo seu papel de vigia dessas atividades. $\mathrm{O}$ autor aponta que tais visões generalistas acabam por ignorar ou minimizar uma série de influências conflitantes fundamentais para compreender a atuação da imprensa como "cão de guarda". No que tange à mídia privada, ignoram que ela precisa manter o interesse da audiência para ser lucrativa, não podendo simplesmente colocar no ar o produto que quiser. Além disso, a mídia privada necessita, como qualquer organização da mesma natureza, sustentar uma legitimidade pública de forma a evitar retribuições sociais. Finalmente, os produtos dessa mídia são influenciados por preocupações profissionais, sociais e éticas dos sujeitos envolvidos em sua produção, indivíduos esses marcados e inseridos tanto em uma cultura própria do sistema dos media como também de seu lugar social.

A partir dessas considerações, chega-se a um modelo de imprensa em que diversos interesses e influências contraditórias se equilibram de forma complexa em um sistema marcado pelo pluralismo dos veículos jornalísticos, por lógicas próprias e pela constante interação com outros sistemas. O papel de vigilância da imprensa precisa ser reavaliado a partir dessas características, que funcionam, em certa medida, como limitações para tal função. Há, por exemplo, interesses que podem levar a imprensa a esconder certas ações prejudiciais aos públicos, assim como pressões para que essas mesmas ações venham à tona e sejam denunciadas - como a perspectiva de um "furo" jornalístico, ou a possibilidade de 
perder prestígio se não denunciarem tais fatos. Enquanto no campo de estudo da comunicação política essa compreensão sistêmica sobre a função de vigilância da imprensa já é trabalhada nos últimos anos (MAIA, 2008), ela pouco figura nas discussões sobre a atuação pública das organizações privadas.

A atuação das redes de vigilância da sociedade civil especificamente sobre as práticas abusivas de comunicação desenvolvidas pelas organizações privadas traz subsídios para pensar o papel de vigilância da imprensa. Em especial, elas revelam elementos e tensões que estabelecem limitações de outra ordem para a função de "cão de guarda", originadas de uma constatação: a mídia está quase sempre implicada nessas práticas, já que elas são, na sua essência, voltadas para a conquista da visibilidade pública. Podemos formular três cenários sobre como essa implicação ocorre. O primeiro é um cenário limítrofe, em que a imprensa é a própria autora de uma dessas práticas. Ela pode orquestrar uma ação abusiva voltada para a manipulação da opinião pública, engendrando ela própria fatos e notícias falsos para influenciar de forma fraudulenta o debate público, tendo em conta seus interesses corporativos. A caracterização deste cenário como limite está diretamente relacionada com o já discutido sistema de interesses conflitantes que marca a atuação da mídia, na medida em que representa um alinhamento de influências quase sempre contraditórias - como questões profissionais e éticas dos envolvidos na fraude e a necessidade de legitimação pública.

O segundo cenário é o envolvimento deliberado da mídia em práticas eticamente questionáveis de corporações que visam influenciar a opinião pública. Tal fato ocorre quando as práticas em questão se alinham aos próprios interesses da mídia. Tal alinhamento não precisa ser necessariamente político - talvez a dimensão de mais fácil compreensão -, mas pode ocorrer por interesses econômicos, logísticos, competitivos e outros. Esse ponto aumenta ainda mais a complexidade existente na questão na medida em que, desde o primórdio das práticas de relações públicas, muitas delas são pensadas e calculadas pelas corporações justamente tendo em conta os possíveis interesses da mídia (BERNAYS, 2004).

Um exemplo é a prática de Video News Releases (VNR's), popular em firmas americanas de relações públicas após a década de 1980 e figura constante entre as denúncias da rede de vigilância civil (STAUBER; RANPTOM, 1995, p. 184; 2003, p. 87). A prática consiste na criação de um vídeo com mensagens do interesse dos seus criadores, mas pensado e formatado para ser veiculado em jornais televisivos como uma notícia comum, não sendo identificada sua origem. Apela, assim, para o interesse da imprensa televisiva em conseguir pautas e imagens - muitas vezes exclusivas - sobre diversos acontecimentos de maneira 
rápida, algo impossibilitado por limitações de recursos financeiros e humanos. Ao mesmo tempo, dialoga com a necessidade que esses veículos possuem de manter uma imagem positiva como forma de conquistar credibilidade e vantagens competitivas - se aquelas imagens fossem utilizadas com a identificação sobre quem as forneceu, poderiam gerar desconforto nos públicos pela falta de critérios jornalísticos ou pela utilização de imagens cedidas por uma fonte com claros interesses na questão. Recorrendo aos interesses da mídia, a prática de VNR's traz benefícios óbvios para seus produtores, que garantem a naturalidade de sua mensagem, como se ela fosse originada da mídia.

Outro caso que também figura entre as denúncias da rede de vigilância civil é a indicação de especialistas alinhados com os interesses das corporações em momentos de crise (STAUBER; RAMPTON, 1995, p.209; 2003, p.197). A lógica é semelhante ao exemplo anterior: no cenário de uma crise, faz parte do modus operandi da imprensa procurar especialistas para pontuar suas matérias, com a necessidade de encontrar rapidamente alguém qualificado e com disponibilidade. As organizações, então, mantêm de prontidão um grupo de especialistas alinhados com sua visão como parte do seu planejamento de crises, cedendo-os para a imprensa nos momentos de necessidade. A imprensa, por sua vez, evita revelar a origem e a ligação do especialista com a organização, sob o risco de manchar sua imagem perante os públicos, permitindo com que o ponto de vista da organização seja defendido como algo imparcial e não enviesado pelos seus interesses privados.

No terceiro cenário, a imprensa é vítima de uma armação e confere visibilidade para a prática abusiva sem conhecimento sobre ela. Entra em jogo um aspecto também presente no cenário anterior: a construção de práticas a partir do reconhecimento do modus operandi da mídia, pensadas para cair diretamente no sistema de circulação midiático. Daniel Boorstin (1954) já chamava a atenção para como os profissionais de relações públicas conseguiam garantir uma presença marcante na mídia para seus pseudo-acontecimentos ${ }^{13}$ : eles eram planejados com essa finalidade, dialogando com as características da mídia e visando a conveniência da imprensa, o apelo dramático e a inteligibilidade. Esse parece ser o cenário mais comum nas denúncias originadas das redes de vigilância civil, figurando na maioria dos casos de astroturfing e front groups, por exemplo.

Cada um destes cenários traz limitações para a função de "cão de guarda" da imprensa. No caso da mídia como autora da prática abusiva, é evidente o conflito que a

13 Acontecimentos falsos, planejados para se passarem por reais. 
impediria de assumir tal função. Já no segundo cenário, o fator limitante é a cumplicidade da mídia com o fato. A denúncia sobre essas práticas impõe a necessidade de justificar os motivos da participação, mesmo que pequena, da mídia naquele esquema, sob o risco de prejuízos para a reputação do veículo. Finalmente, o terceiro cenário também traz entraves relacionados à reputação: para denunciar uma prática em que ele próprio foi enganado, o veículo se veria às voltas com questionamentos sobre os motivos pelos quais o fato noticiado não foi investigado previamente ou as fontes devidamente confrontadas, abrindo espaço para a desconfiança sobre outras matérias que poderiam sofrer da mesma falta de cuidado.

Tais constrangimentos, oriundos da interação da imprensa com as práticas as quais deveria monitorar, se somam àqueles já impostos pela natureza sistêmica complexa da mídia, estabelecendo limitações significativas ao seu desempenho na função de "cão de guarda" das práticas de comunicação abusivas das organizações privadas. É nesse cenário que as redes de vigilância da sociedade civil emergem como uma alternativa, colocando o próprio público no papel central da defesa de seus interesses. Porém, ao mesmo tempo em que a análise dessa rede nos ajuda a compreender as limitações da imprensa, ela permite também observar e refletir sobre a existência de desafios para a atuação dos públicos nessa função.

\section{DESAFIOS PARA ATUAÇÃO DOS PÚBLICOS}

A reconfiguração da vigilância sobre práticas comunicativas das organizações privadas - evidenciada pelo surgimento das iniciativas da sociedade civil - não se deve apenas ao reconhecimento dos limites da imprensa na função de "cão de guarda", mas também às possibilidades trazidas pela internet. $\mathrm{O}$ desenvolvimento da internet deu origem a uma configuração diferenciada da opinião pública, ao permitir que indivíduos exponham e defendam publicamente seus pontos de vistas e interesses de modo direto, afetando sua capacidade de lidar com questões de forma coletiva.

A internet permite aos públicos novos tipos de associação e movimentação, principalmente a partir da ideia de redes de colaboração, algo que está no centro das iniciativas de vigilância civil que apresentamos. O SourceWatch traz na sua página inicial a afirmação que o site é "construído por pessoas ordinárias, como você" e que todos são bem vindos para trabalhar em conjunto. A ideia é que os públicos, através da colaboração, possam se organizar em rede de modo a somar esforços para superar suas limitações e defender os seus próprios interesses, proporcionando um enfrentamento das organizações numa escala que 
não era possível anteriormente e deixando para trás alguns dos constrangimentos inerentes à atuação da imprensa como uma instância de vigilância. É importante, porém, refletir sobre os desafios encarados pelas redes de vigilância civil para atingir seus objetivos, dos quais destacamos três que consideramos cruciais.

O primeiro desafio para a atuação dos públicos na função de vigilância é a credibilidade. Como Alexander (2003) aponta, a credibilidade da imprensa está diretamente relacionada com sua capacidade de manter a crença das audiências de que sua atuação é no sentido de descrever o mundo e os acontecimentos de maneira objetiva e isenta. Mesmo que determinados veículos ou práticas da imprensa sejam encarados com desconfiança pelos públicos, algo dessa crença permanece socialmente difundida. A credibilidade da imprensa é um de seus atributos essenciais, sendo um fator primordial à função de "cão de guarda", ao conferir legitimidade para denúncias.

A efetividade das iniciativas da sociedade civil na função de vigilância depende da conquista de uma credibilidade nos mesmos moldes daquela ostentada pela imprensa. Nesse sentido, devem se mostrar objetivas, pautadas em fatos e isentas da influência de interesses privados. Uma das táticas para tanto é o cuidado com posturas radicais. O CMD é um bom exemplo, evitando denúncias ou repúdio generalizado sobre a atividade de relações públicas, adotando uma postura focada em casos específicos de práticas abusivas desempenhadas por profissionais da área. Logo na primeira obra publicada pelo CMD, Stauber e Ranptom (1995) reconhecem que as técnicas de relações públicas não são inerentemente más, e afirmam que muitos praticantes são engajados em atividades que beneficiam os públicos. Ao evitar posturas generalizantes, realçam sua isenção e objetividade.

Outra tática para abordar a questão da credibilidade é a ênfase no "quem fala". Há um grande foco nas qualificações pessoais sobre aqueles que escrevem e dirigem sites como o PRWatch e o SpinWatch, com extensos - e constantemente citados - perfis que listam as atividades e formações de cada um dos envolvidos com os projetos, justificando sua propriedade para exercer o papel de vigilância. O imperativo de credibilidade acaba entrando em conflito com a ideia de uma rede colaborativa de vigilância formada e mantida pelos cidadãos, já que estabelece constrangimentos para a participação: nem todo cidadão reúne as qualificações necessárias para ser reconhecido como alguém com propriedade para fazer uma denúncia séria.

O enfoque factual, vital para construção de credibilidade, impõe um segundo desafio para os públicos na função de vigilância: a necessidade de comprovação das denúncias, o que 
traz à tona o dilema entre segredo e publicidade. Apesar de a transparência figurar como um valor cada vez mais presente no discurso da comunicação organizacional, não é possível ignorar o conflito existente entre esse conceito e a necessidade de atuação estratégica das organizações. É da natureza de determinadas estratégias que sua efetividade esteja atrelada à permanência do segredo sobre elas. Muitas não apenas perdem seu efeito ao serem publicizadas, mas geram constrangimentos para aqueles que as formularam, colocando em risco a reputação de seus idealizadores - e as práticas de comunicação abusivas para influenciar a opinião pública se encaixam nessa descrição.

É possível argumentar que os riscos de publicização de tais estratégias desencorajariam o seu uso, mas as denúncias da rede de vigilância civil indicam um movimento distinto: elas continuam sendo utilizadas, mas formuladas com maior cuidado para permanecerem em segredo. Para tanto, seguem um caminho semelhante ao que Ellul (1973) identificou nos seus estudos sobre propaganda: não são pautadas em mentiras simples e facilmente refutáveis, mas sim calcadas em ambiguidades capazes de construir cenários complexos que oscilam entre aspectos reais e falsos, criando trilhas difíceis de serem seguidas e tornando progressivamente mais árdua a função de denunciá-las.

As iniciativas civis de vigilância, frente ao desafio de desfazer o intrincado emaranhado construído por essas estratégias, se estruturam ao redor de um apelo aos whistleblowers, termo que designa aqueles que, munidos de informações privilegiadas/internas, denunciam condutas abusivas de governos ou organizações privadas. $\mathrm{O}$ SpinWatch ostenta com destaque o apelo para que aqueles "desiludidos com as práticas de relações públicas dos seus empregadores" entrem em contato e compartilhem suas histórias. As iniciativas do CMD fazem o mesmo, com o SourceWatch contendo a seção "soe o apito", no qual as políticas de proteção aos denunciantes são reforçadas e diferentes canais de comunicação são oferecidos.

Mesmo com a existência de informantes, o processo de comprovação das denúncias permanece complexo. Os denunciantes agem, muitas vezes, por meio do vazamento de documentos que devem ser analisados e verificados, o que requer conhecimentos específicos que permitam compreender as práticas e conexões em jogo. O já citado ALECexposed, por exemplo, teve início com a ação de um whistleblower que disponibilizou mais de 800 documentos, sendo necessários meses de trabalho para que eles fossem verificados e compreendidos. Assim, a barreira do segredo acaba por exigir informações internas e 
conhecimentos especializados para ser superada, gerando constrangimentos para a ação dos cidadãos como uma instância de vigilância.

Finalmente, o terceiro desafio deriva do caminho que a atuação da rede de vigilância civil traça. As denúncias não são dirigidas para o governo, para a mídia ou para as associações profissionais de Relações Públicas, mas sim para os próprios cidadãos. Em um primeiro momento, tentam fornecer informações para que os indivíduos possam se proteger de práticas abusivas. Em seguida, investem em apelos à mobilização dos cidadãos contra tais práticas como campanhas que visam promover o contato direto com legisladores ou agências reguladoras.

Podemos compreender o chamado à ação, que aparece com destaque no CMD, através das concepções de Dewey (1954) sobre o público e o governo. Segundo Dewey, o público é formado por aqueles que se veem afetados indiretamente pelas consequências de transações sociais e que, por esse motivo, tentam exercer controle sobre elas. O governo surge como uma organização política do público, se ocupando da regulamentação de ações sociais cujas consequências dizem respeito a interesses comuns. O caminho que a rede de vigilância civil adota é, na sua essência, um processo de formação de um público: busca chamar a atenção para a existência de um problema, desvelando como aquelas práticas afetam os cidadãos, ao mesmo tempo em que aponta rumos para que aquele público possa intervir, por meio de suas ações, junto às instancias que detêm o poder de decisão para impedir a persistência de tais práticas.

Os entraves ao processo de formação do público identificados por Dewey nos ajudam a entender aspectos problemáticos da atuação da rede de vigilância civil. Um dos principais desafios segundo o pragmatista americano é que, em um mundo demasiadamente complexo e interconectado, nem sempre há clareza sobre o que afeta os sujeitos. Tal colocação se torna ainda mais relevante quando tratamos de práticas formuladas visando o segredo. Um dilema se forma já que, por um lado, a necessidade de credibilidade faz com que as denúncias sejam apresentadas com forte apelo factual, desvelando minúcias de práticas cada vez mais complexas, enquanto que, por outro, a complexidade dessas denúncias cria barreiras para o público, que não consegue acompanhar o que está sendo dito sem um conhecimento prévio.

Mesmo nas denúncias mais pontuais do PRWatch, o cidadão é confrontado com uma grande variedade de nomenclaturas, siglas e referências. O risco é que, na busca pela credibilidade, essas denúncias acabem ficando restritas apenas a um conjunto de iniciados que 
dominam o assunto. Se o objetivo é intervir no processo de tomada de decisões governamentais através da pressão pública, é necessária a formação de um público amplo.

É nesse sentido que a imprensa retorna à cena, já que pode colocar em circulação e reverberar as denúncias da rede de vigilância civil, superando suas limitações. Atuando como uma caixa de ressonância, a mídia é fundamental para atingir um número significativo de indivíduos e fomentar um debate público capaz de gerar a ação necessária para intervir junto aos órgãos decisórios. Estamos, assim, diante de um cenário complexo e permeado de constrangimentos, no qual a prática de vigilância civil é direcionada para os próprios públicos, mas necessita da visibilidade conferida pela imprensa ao mesmo tempo em que a denuncia como parte do problema.

\section{CONSIDERAÇÕES}

Retornamos, enfim, ao questionamento inicial do presente trabalho: a quem cabe a vigilância sobre a atuação pública das organizações privadas? Em primeiro lugar, evidenciouse que tal responsabilidade não pode ser colocada apenas sobre a imprensa, pois ela é permeada por entraves - impostos pela sua natureza sistêmica complexa e pela interação com as práticas que ela deveria monitorar - que restringem seu desempenho nessa função.

Os próprios públicos, munidos das possibilidades de colaboração trazidas pela internet, surgem como uma alternativa. No final, em qualquer caso, a vigilância é papel dos públicos, como apresenta Dewey. Tanto a imprensa quanto o poder público exercem vigilância em nome do público. De certo modo, as redes civis pretendem organizar a ação civil de vigilância, buscando uma colaboração mais direta dos públicos. Porém, não é possível adotar uma postura exageradamente otimista, na qual as redes da sociedade civil garantiriam uma constante e adequada vigilância sobre as organizações. Por mais que a atuação direta do público evite algumas das tensões inerentes ao desempenho da imprensa na função de vigilância, há novos desafios e constrangimentos que impõem limites aos esforços civis, como a necessidade de construção da credibilidade e a comprovação de práticas complexas formuladas para se manterem em segredo. A imprensa também não desaparece ou deixa de exercer alguma vigilância devido ao surgimento das redes civis, estabelecendo com elas novas dinâmicas e tensões, sendo importante, inclusive, observar como a visibilidade conferida pela imprensa às denúncias realizadas pela rede de vigilância civil é um fator crucial para que essas possam intervir junto às instâncias de decisão governamental. 
Dessa forma, não há uma resposta final para a questão da vigilância, que permanece aberta e problemática, mas sim novas reflexões sobre os pormenores que a caracterizam. A compreensão sobre as limitações da imprensa e dos públicos na função de "cão de guarda" sugere novas frentes de investigação futura. Um exemplo é como os desafios impostos às redes de vigilância civil parecem minar a própria noção de colaboração nelas presente ao demandar uma atuação cada vez mais especializada, trazendo implicações que devem ser pensadas.

A investigação exaustiva sobre a realidade brasileira no que tange à atuação destas redes de vigilância civil não figura entre os objetivos do presente artigo, conformando uma abordagem que carece de renovados esforços de pesquisa. Mas, nos parece pertinente refletir, ainda que preliminarmente, sobre o tema em nosso país.

Durante nossa pesquisa, não encontramos no Brasil iniciativas civis sistematizadas especificamente para a denúncia de práticas de comunicação das organizações privadas. Porém, não podemos concluir apressadamente que não há vigilância. Além de um enfrentamento pouco sistematizado em redes sociais, é possível encontrar indícios de um monitoramento indireto por parte de observatórios, tanto naqueles voltados para políticas públicas - que eventualmente captam alguma prática suspeita - como também naqueles direcionados para a atuação da mídia. O maior exemplo é o Observatório da Imprensa ${ }^{14}$, focado na crítica jornalística. Entre sessões como "Observatório da Propaganda" e "Empresas e Mídia", a iniciativa conta com artigos que muitas vezes apreendem incoerências e desonestidades da propaganda e da comunicação organizacional. É, porém, uma atuação que difere daquela encontrada na rede de vigilância civil exposta anteriormente, pois conta com o predomínio de um viés crítico e não de denúncia. Mesmo quando trata de casos específicos, o observatório caminha para uma reflexão crítica sobre o assunto em pauta.

Nesse sentido, nos parecem pertinentes também esforços futuros para compreender como a ausência dessa rede voltada para uma denúncia específica impacta o enfrentamento das organizações privadas por parte do público, e também da imprensa, em nosso país.

\section{REFERÊNCIAS}

${ }^{14}$ Disponível em: <www.observatoriodaimprensa.com.br>, acesso em 20 de ago. de 2013. 
ALEXANDER, J. The Civil Sphere. New York: Oxford University Press, 2006.

BERNAYS, E. Propaganda. New York: Ig Publishing, 2005.

BOORSTIN, D. The image: a guide to pseudo-events in America. New York: Vintage Books, 1992.

CHOMSKY, N.; HERMAN, S. E. Manufacturing consent: the political economy of the mass media. New York: Pantheon Books, 2002.

CURRAN, J. Rethinking Media and Democracy. In: CURRAN, J; GUREVITCH, M. Mass media and society. London: Arnold, 2000. p. 120-154.

DEWEY, J. The public and its problems. Ohio: Swallow Press Books, 1954.

ELLUL, J. Propaganda: The Formation of Men's Attitudes. New York: Knopf Doubleday, 1973.

GUNN, E. Exposing ALEC. The Daily Page. Publicado em 05 de out. de 2012. Disponível em: <http://www.thedailypage.com/isthmus/article.php?article=36715>, acesso em 20 de ago. de 2013.

HABERMAS, J. Mudança Estrutural da Esfera Pública. Investigações quanto a uma categoria da sociedade burguesa. Rio de Janeiro: Tempo Brasileiro, 1984.

MAIA, R. Deliberação e mídia. In: MAIA, R. (org.) Mídia e Deliberação. Rio de Janeiro: FGV Editora, 2008

MILLER, D.; DINAN, W. A Century of Spin: How Public Relations Became the Edge of Corporate Power. London: Pluto Press, 2007.

MILLER, D; DINAN, W. Thinker, Faker, Spinner, Spy: Corporate PR and the assault on democracy. London: Pluto Press, 2007.

NORRIS, P. A virtuous circle: political communications in postindustrial societies. Cambridge: Cambridge University Press. 2000

STAUBER, J.; RAMPTON, S. Toxic Sludge is good for you: Lies, damn lies and the Public Relations Industry. Madison: Common Courage Press, 1995.

STAUBER, J.; RAMPTON, S. Trust Us We're Experts!. New York: Tarcher, 2002.

Original recebido em: 14/09/2013

Aceito para publicação em: Novembro de 2013

Márcio Simeone Henriques 
Professor do Departamento de Comunicação Social da Faculdade de Filosofia e Ciências Humanas/UFMG.

Daniel Reis Silva

Mestrando do Programa de Pós-Graduação em Comunicação Social da UFMG. 